\title{
Characterization of Recombinant Dengue-2 Virus Derived from a Single Nucleotide Substitution in the $5^{\prime}$ Noncoding Region
}

\author{
Vijittra Leardkamolkarn, ${ }^{1}$ Wipawan Sirigulpanit, ${ }^{1}$ and Richard M. Kinney ${ }^{2}$ \\ ${ }^{1}$ Department of Anatomy, Faculty of Science, Mahidol University, Bangkok 10400, Thailand \\ ${ }^{2}$ Arbovirus Diseases Branch, Division of Vector-Borne Infectious Diseases, Center for Disease Control and Prevention, \\ Fort Collins, CO 80522, USA
}

Correspondence should be addressed to Vijittra Leardkamolkarn, scvlk@mahidol.ac.th

Received 25 May 2009; Revised 15 October 2009; Accepted 23 December 2009

Academic Editor: Shahid Jameel

Copyright ( 2010 Vijittra Leardkamolkarn et al. This is an open access article distributed under the Creative Commons Attribution License, which permits unrestricted use, distribution, and reproduction in any medium, provided the original work is properly cited.

\begin{abstract}
Variants of wild-type dengue serotype 2 (DEN-2) virus containing nucleotide substitutions at positions 14,15 , or 57 in the $5^{\prime}$ NCR were constructed by PCR-mediated site-directed mutagenesis. All three viruses containing a single point substitution demonstrated attenuation phenotype as evidenced by decreases replication and plaque size in cell culture assay. All three variants were less neurovirulent in newborn mice compared to the wild type. The mutants were immunogenic in adult mice immunogenicity and maintained stable replication characteristics following passage in mice. The variant viruses were competent for replication in Aedes aegypi mosquito vector, albeit at lower levels of infection and dissemination in the mosquito than the wild-type Den-2 16681 virus. Although all of the viruses, including the wild type, were found transmissible in mosquito life cycles, they were found subsequentially decreased in efficiency of infection, transmission, and dissemination rates along the mosquito generations and all of them remained genetically stable.
\end{abstract}

\section{Introduction}

Dengue (DEN) viruses are flaviviruses that cause dengue fever (DF), dengue haemorrhagic fever (DHF), and dengue shock syndrome (DSS) in humans and are transmitted primarily by infected Aedes aegyptii or Aedes albopictus mosquitoes. By immunological and genetic typing, DEN viruses are divided into 4 serotypes including DEN-1, DEN2, DEN-3, and DEN-4. Secondary infection of humans with a DEN serotype that differs from the serotype of an initial DEN infection often results in illness of greater severity. This disease severity has been attributed to antibody dependent enhancement and increased activation of chemokines. Unsuccessful control of the mosquito vectors of DENs has resulted in increased incidence of dengue disease in several Southeast Asian countries, and the virus is currently endemic in tropical regions worldwide. The optimal strategy for preventing dengue disease appears to be vaccination. However, there is currently no safe and effective DEN vaccine approved for human use, although a number of DEN vaccine candidates are in preclinical development or in clinical trials. Significant obstacles to vaccine development include the need to develop a tetravalent vaccine that protects recipients against all four DEN serotypes, and the lack of a relevant animal model for dengue pathogenesis.

The DEN viral genome is a single-stranded positivesense RNA molecule containing about 11,000 bases and is organized as follows: $5^{\prime}$ noncoding region $\left(5^{\prime}\right.$-NCR), 3 structural genes encoding capsid $(\mathrm{C})$, premembrane/membrane (prM/M) and envelope (E) proteins, 7 nonstructural (NS) genes encoded for NS1, NS2A, NS2B, NS3, NS4A, NS4B, and NS5 proteins, and $3^{\prime}$ NCR. In the virus-infected cell, the 10 coding genes are translated from a single long open reading frame into a polyprotein that is processed into the individual proteins by both cellular and virus-specified enzymes. The mechanisms of flavivirus replication and translation have been widely studied, and the involvement of both $5^{\prime}$ and $3^{\prime}$ NCRs has been well documented [1-5]. Mutations in the $5^{\prime}-$ NCR of RNA viruses such as poliovirus [6, 7], Venezuelan equine encephalitis and Sindbis alphaviruses $[8,9]$, and 
the DEN-2 16681 virus $[10,11]$ have resulted in varying degrees of attenuation of viral virulence. RNA secondary structure in the $5^{\prime}$-NCR appears to be involved in viral replication [12-14]. Mutations that disrupt base pairing within complementary sequences at the $5^{\prime}$ or $3^{\prime}$ ends of DEN genomic RNA can dramatically decrease RNA synthesis [12].

One of the DEN viruses that has been shown to have potential as an effective vaccine component of a tetravalent DEN vaccine is the live-attenuated DEN-2 PDK-53 strain, which has appeared to be safe and effective in clinical trials [15-17]. The PDK-53 virus exhibits a number of phenotypic markers often associated with viral attenuation, including small plaque size, decreased replication in mosquito cells, temperature sensitivity, attenuation of neurovirulence in suckling mice, and reduced viremia in monkeys compared to the wild-type parental DEN-2 virus, strain 16681 [10]. The apparent attenuated phenotypic markers of the PDK-53 virus are encoded by a nucleotide mutation at position 57 in the 5'NCR-57 and two other mutations that encode amino acid changes at amino acid positions NS1-53 and NS3-250 [10]. These genetic markers of attenuation were identified by utilizing infectious cDNA clones of the DEN-2 16681 virus and its vaccine derivative, strain PDK-53 $[10,11]$. The cDNA clone of PDK-53 virus has been used to engineer chimeric vaccine candidates that express the prM/E region of DEN-1, DEN-3, and DEN-4 viruses, as well as West Nile virus, in the attenuated genetic background of the DEN-2 PDK-53 virus. These chimeric viruses were shown to retain the phenotypic markers of the PDK-53 virus, relative to the wild-type DEN$1,-3$, and -4 viruses and West Nile virus [18-20].

Of the three genetic markers of DEN-2 PDK-53 attenuation, only the $5^{\prime}$-NCR-57 locus has shown a propensity to revert to the wild-type residue [21]. In this study, we constructed and characterized several variants of DEN-2 16681 virus that contained a single nucleotide substitution in the $5^{\prime}$ NCR to determine if other attenuating mutations in this region could be identified and perhaps incorporated into a second generation, PDK-53-based candidate vaccine. We previously showed that a number of mutations in the $5^{\prime}$-NCR, particularly those involving deletions of bases, were lethal. Here, we used the M-fold software [22], which predicts RNA secondary structure, to engineer single point mutations at genomic nucleotide positions 14, 15, and 57 that were predicted to have only minor effect on the stemstructure in the $5^{\prime}$-NCR. The variant viral phenotypes were evaluated for possible markers of attenuation.

\section{Materials and Methods}

2.1. Construction of DEN-2 5'-NCR Mutants. The infectious cDNA clone, designated pD2/IC-30P-A, of DEN2-16681 virus served as template for mutagenesis [11]. A small subclone (plasmid pF1) containing the $\mathrm{T} 7$ promoter and DEN genomic nucleotide positions $1-1380$ was used as template for PCR-mediated site-directed mutagenesis. Single nucleotide substitutions in the $5^{\prime}$-NCR were performed by designed primer pairs that contained the desired nucleotide substitutions at positions 14 ( $\mathrm{C}$ changed to $\mathrm{A}$ ), 15 ( $\mathrm{G}$ changed to $\mathrm{U})$, and 57 ( $\mathrm{C}$ changed to $\mathrm{U})$. PCR cycles were set at $94^{\circ} \mathrm{C}$ for $15 \mathrm{sec}, 50^{\circ} \mathrm{C}$ for $30 \mathrm{sec}$, and $72^{\circ} \mathrm{C}$ for $1 \mathrm{~min}$ for 35 cycles. PCR products were separated by electrophoresis in $0.8 \%$ agarose gels (TBE buffer), then extracted from the agarose and purified over spin columns. The purified cDNA from PCR products was ligated into the appropriate restriction enzyme sites of plasmid pF1, and the recombinant plasmid was transformed into E. coli XL-1 Blue by electroporation. The resulting variant $\mathrm{pF} 1$ plasmids were sequenced to validate the presence of the desired mutation, and cDNA cassettes containing designed mutations were reintegrated between the SstI and SphI sites in the full-length pD2IC/30PA clone. The ligated products were electroporated into E. coli XL-I Blue, and those infectious clone plasmids (pD2$14.5^{\prime} \mathrm{M},-15.5^{\prime} \mathrm{M}$, and $-57.5^{\prime} \mathrm{M}$ ) containing the correct inserts were amplified in, and extracted from, E. coli.

2.2. Transcription of Viral RNA and Derivation of Virus. In vitro transcription of the XbaI-linearized infectious clone plasmids was performed for $2 \mathrm{~h}$ at $37^{\circ} \mathrm{C}$ by using the Ampliscribe $\mathrm{T} 7$ transcription kit (EpiCentre Technologies) and RNA cap structure analog $7 \mathrm{mG}\left(5^{\prime}\right)$ ppp (5') A (New England Biolabs). 200-500 ng plasmid DNA was used for each transcription reaction. The transcribed viral RNA was transfected into LLC-MK 2 cells $(0.5 \mathrm{~mL}$ containing $4-6 \times$ $10^{6}$ cells $/ \mathrm{mL}$ ) by electroporation (Bio-Rad Gene Pulser). The cells were shocked twice, then transferred to a $75 \mathrm{~cm}^{2}$ flask in Dulbecco's modified minimal essential medium (DMEM) containing $10 \%$ fetal bovine serum (FBS) supplemented with penicillin/streptomycin, and finally incubated in a $5 \% \mathrm{CO}_{2}$ incubator at $37^{\circ} \mathrm{C}$. Infection was evaluated by the presence of cytopathic effect (CPE) and DEN-specific immunofluorescence assay (IFA) after 7-10 days in culture. The infectious medium was harvested and made in $20 \%$ in FBS, clarified by centrifugation, and the recombinant viruses were in aliquots at $-70^{\circ} \mathrm{C}$.

\subsection{Characterization of the Recombinant Viruses (D2-5' Ms)}

\subsubsection{Viral Replication in Cell Cultures and in Mosquitoes}

Kinetic of Replication in LLC-MK $\mathrm{K}_{2}$ and in C6/36 Cells. LLC$\mathrm{MK}_{2}$ and C6/36 cells cultured in $75 \mathrm{~cm}^{2}$ flask were infected at a multiplicity of infection (MOI) of $0.001 \mathrm{PFU} /$ cell with DEN-2 16681 (wild type) or D2-5'M (D2-14.5'M, D2$15.5^{\prime} \mathrm{M}$, and $\mathrm{D} 2-57.5^{\prime} \mathrm{M}$ ) virus. Virus was adsorbed for $2 \mathrm{~h}$ to $\mathrm{LLC}-\mathrm{MK}_{2}$ cells at $37^{\circ} \mathrm{C}$ and to $\mathrm{C} 6 / 36$ cells at $28-30^{\circ} \mathrm{C}$. Culture medium was changed to DMEM containing penicillin/streptomycin and 5\% FBS. Then, infected cells were transferred to a $5 \% \mathrm{CO}_{2}$ incubator at the appropriate temperature for cells. Aliquots of culture medium were collected at 48 -h intervals to determine the viral titer. Viral replication kinetics were determined by plaque titration assays in 6-well plates containing confluent monolayers of LLC-MK 2 cells. Mean plaque size diameter was determined for each virus by measuring 20-40 plaques.

Kinetics of Replication in Aedes aegypti Mosquitoes. Female Aedes aegypti mosquitoes were housed in cages at $30^{\circ} \pm$ $2{ }^{\circ} \mathrm{C}, 80 \%$ humidity, and with a $12: 12 \mathrm{~h}$ light: dark period. 
They were reared with a normal rat chow diet and 10\% sucrose solution until infection. Mosquitoes were starved 1 day before being fed with a mixture of blood: DMEM containing $10^{6} \mathrm{PFU}$ of virus: $10 \%$ sucrose in the ratio $0.5: 1.5: 0.5$ until their stomachs became engorged. Two hundred adult female mosquitoes were fed for each virus. Six infected mosquitoes were randomly sampled at day 4-12 postinfection to determine the presence of viral infection by IFA.

Determination of Viral Transmission and Dissemination. Percent infection and dissemination rates were determine at day 21 after oral infection. Virus-infected mosquitoes were sampled ( 25 mosquitoes from each group) and killed by freezing. Head and body portions were severed and squashed on slides, which were treated with prechilled $90 \%$ acetone to fixed antigen. The slides were air dried at room temperature and then analyzed by indirect IFA using the anti-DEN-E protein-specific $3 \mathrm{H} 5$ monoclonal antibody. Positive IFA of the body part indicated oral infection, and positive IFA of head squashes indicated viral dissemination.

Standard Plaque Titration and Plaque Size Determinations. Tenfold serial dilution series of the mutant viral seeds were made in BA-1 diluent. Monolayers of LLC-MK 2 cells were inoculated with $0.2 \mathrm{~mL}$ of diluted virus, and adsorption was performed for $1 \mathrm{~h}$ at $37^{\circ} \mathrm{C}$ and $5 \% \mathrm{CO}_{2}$. Four $\mathrm{mL}$ of agarose overlay medium $(2 \times$ nutrient solution and $2 \%$ agarose solution, $1: 1$ ) was added, and after 7 days of incubation the cultures were overlaid with $2 \mathrm{~mL}$ of agarose overlay medium containing $80 \mathrm{ug} / \mathrm{mL}$ (diluted from $1 \%$ stock) neutral red solution (Gibco) and reincubated in the $\mathrm{CO}_{2}$ chamber. Plaques were quantified daily for 3-4 consecutive days. Plaque sizes were measured, and mean plaque diameter was calculated from 20-40 plaques.

2.4. Temperature Sensitivity Phenotype. Two sets of LLC$\mathrm{MK}_{2}$ cell cultures in $25 \mathrm{~cm}^{2}$ flask were inoculated with virus at MOI of $0.001 \mathrm{PFU} /$ cell, incubated for $2 \mathrm{~h}$ at $37^{\circ} \mathrm{C}$, and then overlaid with $10 \mathrm{~mL}$ of M199 medium containing 5\% FBS. One set of infected cells was incubated for 7-9 days in $5 \% \mathrm{CO}_{2}$ at $37^{\circ} \mathrm{C}$, the other set at $39^{\circ} \mathrm{C}$. Culture media were collected and analyzed to determine for viral titers.

2.5. Neurovirulence in Newborn Mice. Newborn white ICR mice were infected intracranially with $10^{4} \mathrm{PFU}$ of virus in a $0.02 \mathrm{~mL}$ volume. The animals were observed daily for signs of paralysis and death. The body weights of surviving mice were determined every week for 5 weeks.

2.6. Immunoprotection Assay and Viremia in Mice. Female white ICR mice ( 3 wk-old, 9 mice per group) were injected subcutaneously (s.c) with $10^{5}$ PFU of virus. The animals received two s.c. booster immunizations with the same viral dose at day 7 and day 21 . Two weeks after the second boost, at day 35 , the mice were challenged intraperitoneally with $10^{5}$ PFU of wild-type DEN-2 16681 virus. At day 5, 19, and 33, mice were bled by orbital sinus venipuncture. The blood was collected in nonheparinized capillary tubes, and the serum was separated and kept frozen at $-70^{\circ} \mathrm{C}$.
The serum aliquots were tested for anti-DEN-2 neutralizing antibody by serum dilution-plaque reduction neutralization test $\left(\mathrm{PRNT}_{50}\right)$ without addition of exogenous complement. In brief, twofold serial dilutions of heat-inactivated serum (at $56^{\circ} \mathrm{C}, 30 \mathrm{~min}$ ) were incubated overnight at $4^{\circ} \mathrm{C}$ with an equal volume of diluent containing $60 \mathrm{PFU}$ of DEN-2 16681 virus. LLC-MK ${ }_{2}$ cells in 6-well plates were inoculated with the serum-virus mixtures, then, incubated for $90 \mathrm{~min}$ at $37^{\circ} \mathrm{C}$ and $5 \% \mathrm{CO}_{2}$. The plates were treated as described for the plaque titration assay using the double agarose overlay technique. Back titrations of the input wildtype DEN-2 16681 virus were included in duplicate in the assays. The neutralizing antibody titer was identified as the highest serum dilution that reduced the number of input plaques in the test by $50 \%$ or greater. The level of virus circulating in the blood (viremia) was determined by the plaque titration assay.

2.7. Ovarian Transmission of the Virus in 5 Generations of Mosquito Cycle. Female mosquitoes that had been mated with uninfected males were starved 1 day before feeding with blood mixtures containing $10^{6} \mathrm{PFU}$ of virus. The female mosquitoes (Generation 1, or G1) that hatched from eggs from this initial mating were in turn mated, starved, and fed virus-containing blood meals. This procedure was repeated through G5, and adult females from each generation were assayed for viral RNA and infectious viral titers. Percentage of mosquito infection and dissemination was determined by IFA of mosquitoes' body and head tissues (50 mosquitoes from each group).

2.8. Genetic Validation of the Mutants. After replication in cell cultures and in mosquitoes, viral genomic RNAs were extracted and either (a) reverse transcribed with $\mathrm{RAV}_{2}-\mathrm{RT}$ using the $5^{\prime}$ RACE (rapid amplification of $5^{\prime}$ cDNA ends) kit (GIBCO, BRL) to obtain $5^{\prime}$-terminal cDNA sequencing or (b) subjected to RT-PCR using DEN-2-specific primer pairs to amplify segments covering the complete genome for whole genomic sequencing to verify the presence of the desired mutation in the $5^{\prime}$-NCR and lack of spurious mutations in the rest of the genome.

2.9. RNA Secondary Structure Analysis. Viral RNA secondary structure analysis was performed by using the MFold program version 3.1 created by Zuker [22].

\section{Results}

3.1. Viral Replication in Cell Cultures and in Mosquitoes (Figure 1). In LLC- $\mathrm{MK}_{2}$ cells, variant viruses D2-14.5' M, $15.5^{\prime} \mathrm{M}$, and $57.5^{\prime} \mathrm{M}$ replicated to much lower peak titers of $6.8 \pm 0.5,6.9 \pm 0.7$, and $6.3 \pm 0.5 \log _{10} \mathrm{PFU} / \mathrm{mL}$, relative to the peak $8.8 \pm 0.7 \log _{10} \mathrm{PFU} / \mathrm{mL}$ titer of the wild-type 16681 virus (Figure $1(\mathrm{a})$ ). In C6/36 cells, variant viruses D2-14.5'M and $-15.5^{\prime} \mathrm{M}$ also replicated to much lower peak titers $(6.7$ $\left.\pm 0.8,6.2 \pm 0.5 \log _{10} \mathrm{PFU} / \mathrm{mL}\right)$ than the 16681 virus $(8.9 \pm$ $1.1 \log _{10}$ PFU/mL; see Figure 1(b)). However the D2-57.5'M variant replicated to a peak titer of $8.9 \pm 1.1 \log _{10} \mathrm{PFU} / \mathrm{mL}$ that was equivalent to the peak titer of 16681 virus in $\mathrm{C} 6 / 36$ 


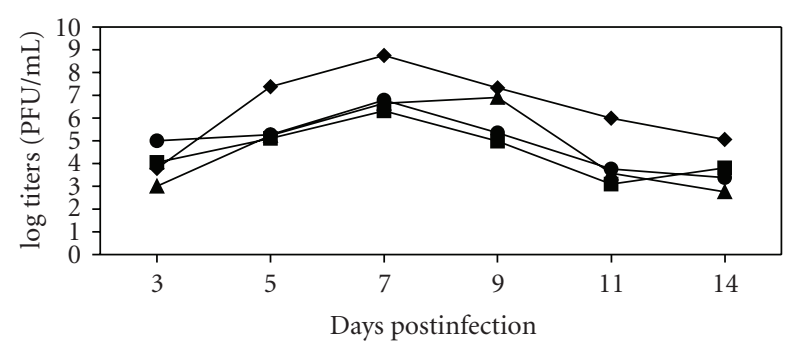

(a) Kinetic of replication of DEN-2 mutants in LLC-MK 2 cells

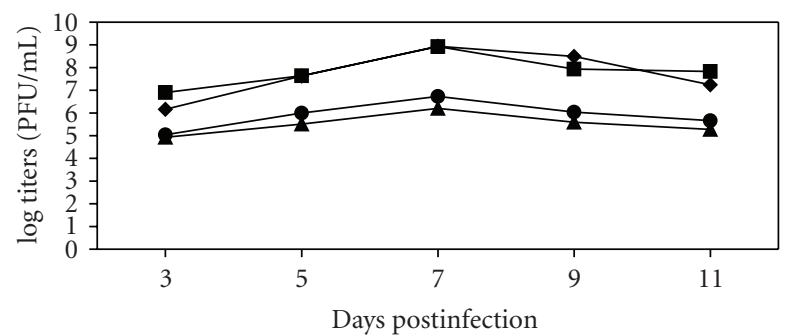

(b) Kinetic of replication of DEN-2 mutants in C6/36 cells

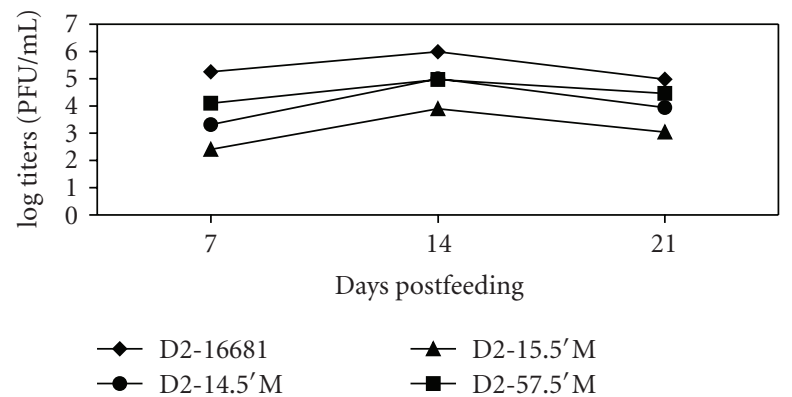

(c) Kinetic of replication of DEN-2 mutants in Aedes aegypti by oral feeding

Figure 1: Kinetic of replication of DEN-2 mutants in LLC-MK 2 cells (a), C6/36 cells (b), and mosquitoes (c).

cells. The latter result contrasts with the results of Butrapet [10], who reported that the $5^{\prime} \mathrm{NCR}-57$ mutant replicated to significantly lower levels than 16681 virus in C6/36 cells. The kinetics of replication of all 3 mutants, particularly the D2$15.5^{\prime} \mathrm{M}$ mutant, were decreased in Aedes aegypti mosquitoes (Figure 1(c)). At day 21, the titer of the D2-57.5'M virus approached that of wild-type virus, while the titers of D2$15.5^{\prime} \mathrm{M}$ and $-14.5^{\prime} \mathrm{M}$ remained depressed (Figure $1(\mathrm{c})$ ).

However, the plaque sizes of D2-14.5'M $(1.17 \pm 0.02 \mathrm{~mm}$ mean plaque diameter), D2-15.5'M (1.16 $\pm 0.02 \mathrm{~mm})$, and D2-57.5'M $(1.49 \pm 0.06 \mathrm{~mm})$ were statistically significantly $(P<.0001)$ smaller from the plaque size of the 16681 virus $(1.99 \pm 0.07 \mathrm{~mm})$ (data not shown). These relative plaque sizes of these four viruses were maintained following passage of the viruses in C6/36 cells and Aedes aegypti mosquitoes (not shown).

3.2. Neurovirulence in Newborn Mice. Newborn ICR mice were challenged intracranially with each of the four viruses in two separate experiments (16 mice each) (Table 1). The wild-type 16681 virus caused $100 \%$ fatality. Virus variants
TAble 1: Neurovirulence Assay of DEN-2 mutants in new born mice.

\begin{tabular}{lcl}
\hline Viruses & \multicolumn{2}{c}{$\begin{array}{c}\text { Neurovirulence } \\
\text { Average survival time } \\
\text { (AST) (days } \pm \text { SD) }\end{array}$} \\
\hline $\mathrm{D} 2-16681$ & $100(32)$ & $4.7 \pm 0.32$ \\
$\mathrm{D} 2-14.5^{\prime} \mathrm{M}$ & $32.5(32)$ & $16.9 \pm 0.67$ \\
$\mathrm{D} 2-15.5^{\prime} \mathrm{M}$ & $31(32)$ & $8.6 \pm 0.61$ \\
$\mathrm{D} 2-57.5^{\prime} \mathrm{M}$ & $31(36)$ & $17.9 \pm 0.68$ \\
\hline
\end{tabular}

TABLE 2: Temperature sensitivity $(t s)$ phenotype in LLC-MK $\mathrm{M}_{2}$ cell and percent of oral infection and dissemination in Aedes aegypti mosquitoes.

\begin{tabular}{lcc}
\hline Viruses & $\begin{array}{c}\text { ts phenotype } \\
\text { (EOP ratio) }\end{array}$ & $\begin{array}{c}\text { Positive IFA head/body } \\
\text { (\% dissemination) } \\
n=25\end{array}$ \\
\hline $\mathrm{D} 2-16681$ & 1.3 & $19 / 24(79 \%)$ \\
$\mathrm{D} 2-14.5^{\prime} \mathrm{M}$ & 1.7 & $11 / 20(55 \%)$ \\
$\mathrm{D} 2-15.5^{\prime} \mathrm{M}$ & 1.2 & $7 / 16(44 \%)$ \\
$\mathrm{D} 2-57.5^{\prime} \mathrm{M}$ & 1.6 & $8 / 19(42 \%)$ \\
\hline
\end{tabular}

$\mathrm{D} 2-14.5^{\prime} \mathrm{M},-15.5^{\prime} \mathrm{M}$, and $-57.5^{\prime} \mathrm{M}$ all resulted in $31 \%-$ $32.5 \%$ mortality. The average survival times (ASTs) of mice challenged with D2-14.5'M, D2-15.5'M, and D2-57.5'M, and which suffered mortality, were statistically significantly greater than the AST of mice challenged with the 16681 virus $(P<.0001)$. Excluding the animals which suffered mortality, the weekly incremental increases in mean body weights were similar for each experimental group during the experimental period.

3.3. Temperature Sensitivity Phenotype in LLC-MK 2 Cells and Percent Infection and Dissemination in Aedes aegypti Mosquitoes. The wild-type 16681 virus, as well as all three of the variant viruses, was not temperature sensitive when replicated in LLC-MK ${ }_{2}$ cells. The 16681 and D2-15.5'M viruses showed similar $37^{\circ} \mathrm{C}$-titer $/ 39^{\circ} \mathrm{C}$-titer ratios of 1.3 and 1.2 , respectively, while the $\mathrm{D} 2-14.5^{\prime} \mathrm{M}$ and $\mathrm{D} 2-57.5^{\prime} \mathrm{M}$ variants had ratios of 1.7 and 1.6, respectively.

The viral competency of each virus in Aedes aegypti mosquitoes was also examined. Adult female mosquitoes were fed blood meals containing virus. The presence of virus in the mosquitoes was assayed by IFA at 21 days after feeding. Positive IFA detection in mosquitoes' bodies indicated susceptibility to viral infection. Nearly all (96\%) of the tested mosquitoes became infected with the wild-type 16681 virus; whereas the three variant viruses resulted in 64$80 \%$ positive infection rate (Table 2 ). Positive IFA detection in mosquitoes' heads indicated viral dissemination from the midgut and the potential for transmission of the virus. Of the 25 mosquitoes tested in each virus group, the three variant viruses exhibited much reduced rates of dissemination to the head, $42 \%-55 \%$, than did the wild-type 16681 virus (79\%). 


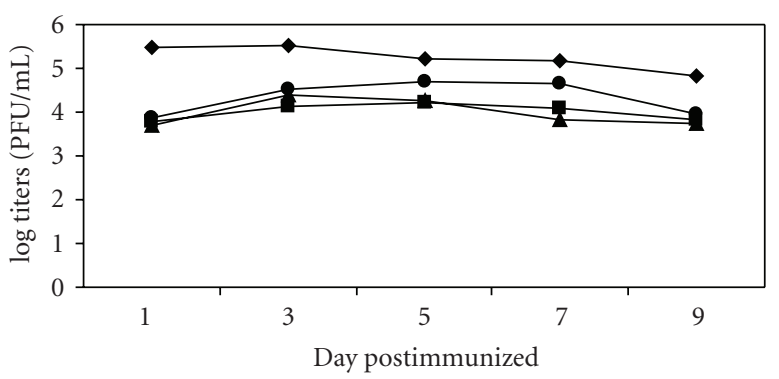

(a) Kinetic of viremia of DEN-2 mutants at the day of immunized

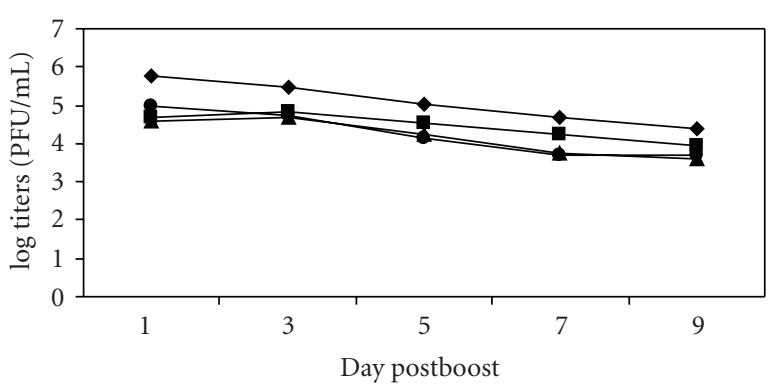

(b) Kinetic of viremia of DEN-2 mutants at the day of boost 1st

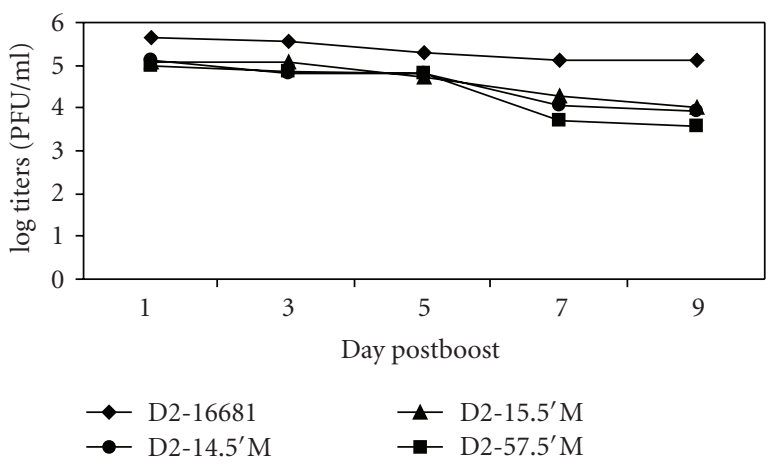

(c) Kinetic of viremia of DEN-2 mutants at the day of boost 2 nd

FIgURe 2: Kinetic of viremia of DEN-2 mutants in mice at day of immunized (a), boost 1st (b), and boost 2 nd (c).

3.4. Immunoprotection Assay and Level of Viremia in Mice. To determine whether the mutant viruses could be maintained in the blood circulation and be able to boost mice immune response, the blood taken from immunized mice were titered for replication kinetic. The mutant viruses exhibited significantly lower replication efficiency than the wild type (Figure 2). The viremia titers of D2-5'M were significant difference from D2-16681 viruses $(P=.002-.0001)$. The plaque phenotypes of all the viruses were not significantly changed from the primary derived viruses (data not shown).

The neutralizing antibody production from immunized mice with D2-16681and $\mathrm{D} 2-5^{\prime} \mathrm{M}$ determined at day 5, 19,33 , and 38 by $\mathrm{PRNT}_{50}$ assay showed some extent of inducing immunogenic response. Obviously, the mutant viruses induced 2-8 folds less titers than the wild type (Table 3).

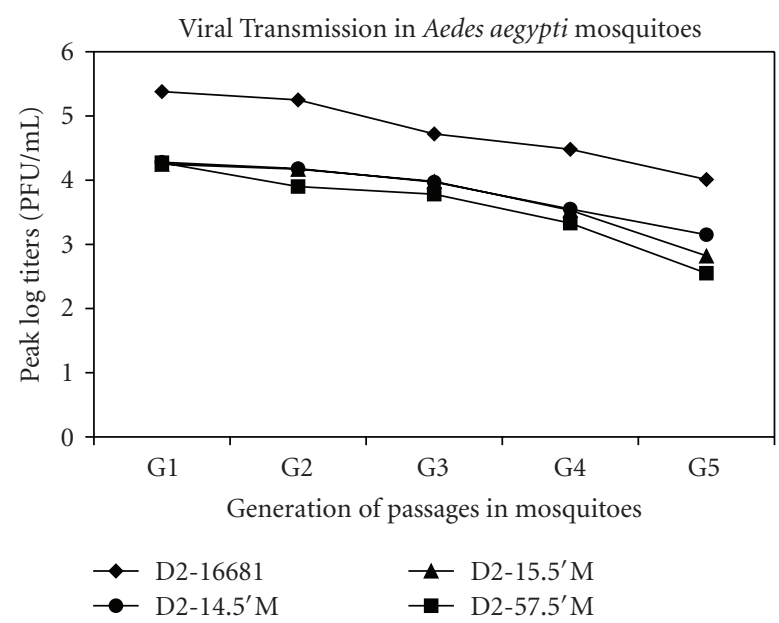

FIGURE 3: Viral transmission and titers in each generation.

3.5. Viral Transmission in Aedes aegypti Mosquitoes and Genetic Validation of the Mutants. To determine the replication phenotype of virus in the mosquito progeny, viruses were isolated from ovarian transmitted mosquitoes at 1-5 generations. The result indicated that the viruses isolated from mosquitoes infected with $\mathrm{D} 2-5^{\prime} \mathrm{M}$ and $\mathrm{D} 2-16681$ maintained their growth and replication characteristics, in which $\mathrm{D} 2-5^{\prime} \mathrm{M}$ viruses were lower efficient than D216681 (Figure 3). The percent of infection and dissemination rate were also reduced (Table 4). Furthermore, full-length nucleotide sequencing analysis of the virus before mosquito ingestion and after 5 generations of vector transmission indicated stable RNA sequences of the viral gene (data not showed).

3.6. Viral RNA Secondary Structure Analysis. Substitution mutation at nucleotide position 14,15 , and 57 in $5^{\prime}$ NCR of D2 gene caused mild alteration of RNA secondary structure from that of the wild type (Figure 4(a)). At the stem-2 and loop-2 region, D2-14.5'M showed a small splitting stem (Figure 4(b)), D2-15.5'M showed shortening stem and widening loop (Figure 4(c)), while D2-57.5' M maintained a similar pattern to the wild type (Figure $4(\mathrm{~d})$ ).

\section{Conclusion and Discussion}

The recombinant viruses that carried a single point substitution in the conserved $5^{\prime} \mathrm{NCR}$ gene of DEN-2 were genetically stable in the Aedes aegypti mosquito vector and in mice. The variant viruses exhibited decreased replication efficiency in LLC-MK 2 and, except for the D2$57.5^{\prime} \mathrm{M}$ virus which replicated as well as the 16681 virus, in C6/36 cells as well. All three variants had decreased replication profiles in Aedes aegypti mosquitoes. These three viruses produced smaller plaque and were less virulent in newborn mice compared to the wild-type virus. An independently engineered variant at 5'NCR-57 also exhibited similar small plaque size and decreased neurovirulence level for newborn mice, but differed from the D2-57.5'M 
TABLE 3: Immunoprotection assay of DEN-2 mutants.

\begin{tabular}{lcccc}
\hline & \multicolumn{4}{c}{ PRNT titer against D2-16681 virus in pooled sera } \\
Viruses & Immunized (day 5th) & Boost 1 (day 19th) & Boost 2 (day 33rd) & Challenged (day 38th) \\
\hline D2-16681 & 160 & 640 & 1280 & 5120 \\
D2-14.5'M & 20 & 80 & 160 & 640 \\
D2-15.5'M & 80 & 160 & 160 & 1280 \\
D2-57.5'M & 40 & 160 & 320 & 2560 \\
\hline
\end{tabular}

TABLE 4: Percent Infection and Dissemination in generation 1-5.

\begin{tabular}{|c|c|c|c|c|c|c|c|c|}
\hline \multirow{2}{*}{ Viruses } & \multicolumn{2}{|c|}{ D2-16681 } & \multicolumn{2}{|c|}{$\mathrm{D} 2-14.5^{\prime} \mathrm{M}$} & \multicolumn{2}{|c|}{$\mathrm{D} 2-15.5^{\prime} \mathrm{M}$} & \multicolumn{2}{|c|}{$\mathrm{D} 2-57.5^{\prime} \mathrm{M}$} \\
\hline & $\begin{array}{l}\text { Infection } \\
(\%)^{\mathrm{a}}\end{array}$ & $\begin{array}{l}\text { Dissemination } \\
(\%)^{\mathrm{b}}\end{array}$ & $\begin{array}{l}\text { Infection } \\
(\%)\end{array}$ & $\begin{array}{l}\text { Dissemination } \\
(\%)\end{array}$ & $\begin{array}{l}\text { Infection } \\
(\%)\end{array}$ & $\begin{array}{l}\text { Dissemination } \\
(\%)\end{array}$ & $\begin{array}{l}\text { Infection } \\
(\%)\end{array}$ & $\begin{array}{l}\text { Dissemination } \\
(\%)\end{array}$ \\
\hline G1 & $31(62 \%)$ & $24(77 \%)$ & $19(38 \%)$ & $10(53 \%)$ & $21(42 \%)$ & $12(57 \%)$ & $16(32 \%)$ & $7(44 \%)$ \\
\hline G2 & $42(48 \%)$ & $20(47 \%)$ & $16(32 \%)$ & $5(31 \%)$ & $23(46 \%)$ & $10(43 \%)$ & $15(30 \%)$ & $5(33 \%)$ \\
\hline G3 & $37(74 \%)$ & $15(40 \%)$ & $18(36 \%)$ & $7(39 \%)$ & $17(34 \%)$ & $5(29 \%)$ & $5(10 \%)$ & $3(60 \%)$ \\
\hline G4 & $20(40 \%)$ & $14(70 \%)$ & $16(32 \%)$ & $7(44 \%)$ & $19(38 \%)$ & $5(26 \%)$ & $9(18 \%)$ & $1(11 \%)$ \\
\hline G5 & $18(36 \%)$ & $6(33 \%)$ & $12(24 \%)$ & $4(33 \%)$ & $8(16 \%)$ & $3(38 \%)$ & $4(8 \%)$ & $2(50 \%)$ \\
\hline
\end{tabular}

${ }^{a}$ number of IFA positive mosquitoes in gut part/number of mosquitoes $(n=50) \times 100$.

${ }^{b}$ number of IFA positive mosquitoes in head part/number of IFA positive mosquitoes in gut part $\times 100$.

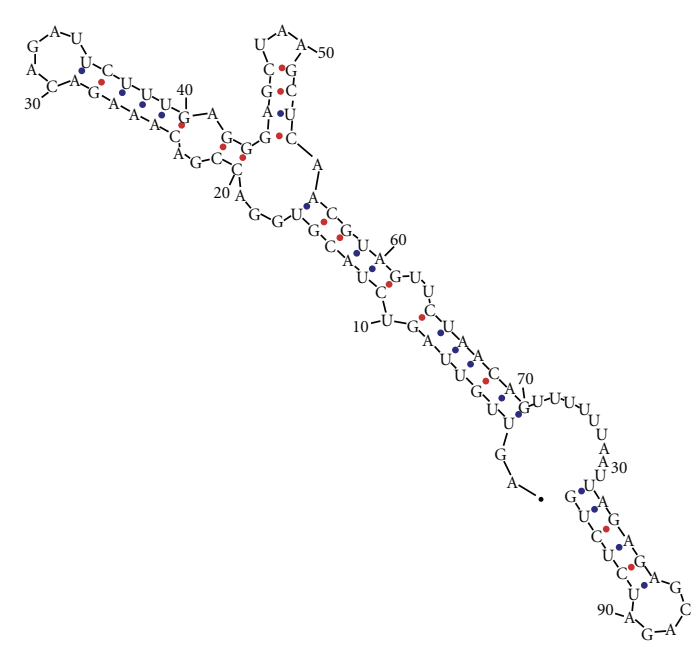

(a) DEN-2 16681

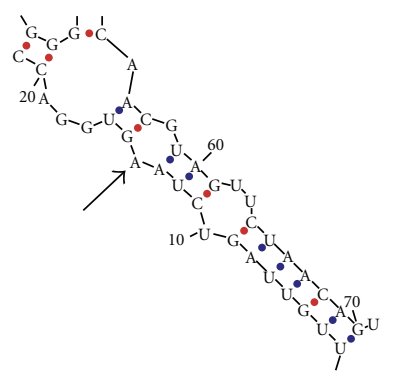

(b) $\mathrm{D} 2-14.5^{\prime} \mathrm{M}$

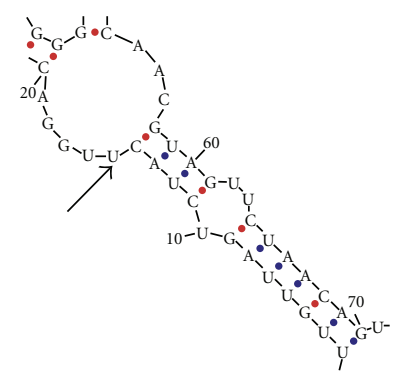

(c) $\mathrm{D} 2-15.5^{\prime} \mathrm{M}$

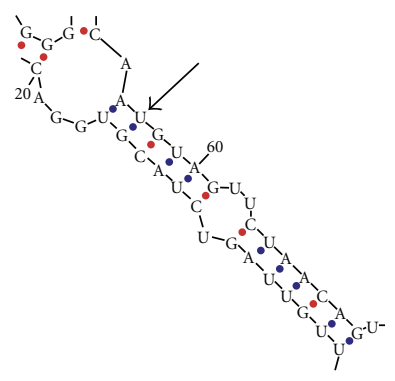

(d) $\mathrm{D} 2-57.5^{\prime} \mathrm{M}$

FIGURE 4: Predicted RNA secondary (stems and loops) structure of $5^{\prime}$ NCR of DEN2-16681 (stem1 = bases 3-9 and 64-71, stem2 = bases 11-16 and 56-61). The arrow represented the mutation position. 
results reported here in having a decreased replication profile in C6/36 cells [10]. We are presently unable to explain the discrepancy in the $\mathrm{C} 6 / 36$ replication profiles between the D2-5' $\mathrm{M}$ virus and the $5^{\prime} \mathrm{NCR}-57$ virus reported previously.

Based on the modified in vitro and in vivo phenotypes of the variant viruses, these viruses were considered to have vaccine potential. Mice immunized with three high doses $\left(10^{5} \mathrm{pfu}\right.$ each) of each of the variant viruses developed significant levels of neutralizing antibodies and challenging with DEN2-16681. The mice infection with DEN2-16681 and its derived mutants, however, demonstrated some degree of neurovirulence including paralysis and weakness after 38 days and at least 1 mouse from each group died during the assay. Although involving only a minor alteration in the $5^{\prime} \mathrm{NCR}$ predicted RNA secondary structure [22], the single base-substitution mutations at $5^{\prime} \mathrm{NCR}$ positions 14,15 , and 57 resulted in significant alterations in in vitro and in vivo viral. A single nucleotide substitution at position 69 of the American DEN-2 genotype, leading to a minor change (shortening) of stem-1, has been shown to encode a low-virulence genotype [23]. In our previous study, we were unable to derive infectious viruses from multiple-site ( $>2$ nucleotides) substitutions between $5^{\prime} \mathrm{NCR}$ positions 56-61 of the [24]. The present study provides further evidence for the potential biological significance of single nucleotide substitutions that cause apparently minor perturbations in RNA secondary structure in the $5^{\prime} \mathrm{NCR}$. Characterization of the mutants in Aedes aegypti mosquito suggested that they were competent for replication in this vector. Although both DEN-2 wild type and the D2-5'M viruses were capable of vertical transmission in Aedes aegypti, the mutants' growth and replication in infected mosquitoes and the progenies were less efficient than those of the wild type. The rates of viral infection and dissemination were significantly decreased after 5 generations of mosquito life cycle. The lower transmission and dissemination in the mosquito suggested the poorer potency of the mutants to be transmitted to human host. DEN216681 wild-type and the derived D2-5'M viruses remained genetically stable in the vector even after passage for 5 generations.

In conclusion, the $\mathrm{D} 2-14.5^{\prime} \mathrm{M}$ and $\mathrm{D} 2-15.5^{\prime} \mathrm{M}$ variant viruses exhibited in vitro and in vivo phenotypic markers of attenuation that were similar to many of the markers reported earlier for the $5^{\prime} \mathrm{NCR}-57$ mutation [10]. The 5'NCR-57 C(wild-type)-to- $\mathrm{T}$ (vaccine candidate) mutation is one of the three dominant mutations that have been reported to encode the attenuated phenotype of the candidate DEN-2 PDK-53 vaccine virus [10]. The D2-57.5'M mutation has been shown to have a propensity to revert to the wild-type $\mathrm{C}$ residue upon serial passage in Vero cell culture [21]. Incorporation of one or both D2-14.5'M and $\mathrm{D} 2-15.5^{\prime} \mathrm{M}$ mutations together with the $\mathrm{D} 2-57.5^{\prime} \mathrm{M}$ mutation may lead to a more stable attenuation locus in the $5^{\prime} \mathrm{NCR}$ of the DEN-2 viral genome. The singlepoint mutants appeared to retain their plaque size and replication phenotypes following passage in mice and vertical transmission in mosquitoes.

\section{Acknowledgments}

This study was supported by the Royal Golden Jubilee PhD Programme of Thailand Research Fund, Thailand-Tropical Diseases Research Programme (T2), the National Center for Genetic Engineering and Biotechnology (BIOTEC), and the National Science and Technology Development Agency (NSTDA), Thailand. The authors thank Mr. Nattanej Luplertlop for technical assistant.

\section{References}

[1] R. Andino, G. E. Rieckhof, P. L. Achacoso, and D. Baltimore, "Poliovirus RNA synthesis utilizes an RNP complex formed around the 5 '-end of viral RNA," The EMBO Journal, vol. 12, no. 9, pp. 3587-3598, 1993.

[2] A. Cahour, A. Pletnev, M. Vazeille-Falcoz, L. Rosen, and C.J. Lai, "Growth-restricted dengue virus mutant containing deletions in the $5^{\prime}$ noncoding region of the RNA genome," Virology, vol. 207, no. 1, pp. 68-76, 1995.

[3] R. M. del Angel, A. G. Papavassiliou, C. Fernandez-Tomas, S. J. Silverstein, and V. R. Racaniello, "Cell proteins bind to multiple sites within the $5^{\prime}$ untranslated region of poliovirus RNA," Proceedings of the National Academy of Sciences of the United States of America, vol. 86, no. 21, pp. 8299-8303, 1989.

[4] G. P. Pogue, X. Q. Cao, N. K. Singh, and H. L. Nakhasi, " 5 ' sequences of rubella virus RNA stimulate translation of chimeric RNAs and specifically interact with two hostencoded proteins," Journal of Virology, vol. 67, no. 12, pp. 7106-7117, 1993.

[5] S. B. Stein, L. Zhang, and R. P. Roos, "Influence of Theiler's murine encephalomyelitis virus $5^{\prime}$ untranslated region on translation and neurovirulence," Journal of Virology, vol. 66, no. 7, pp. 4508-4517, 1992.

[6] A. J. Macadam, S. R. Pollard, G. Ferguson, et al., "The 5' noncoding region of the type 2 poliovirus vaccine strain contains determinants of attenuation and temperature sensitivity," Virology, vol. 181, no. 2, pp. 451-458, 1991.

[7] Y. V. Svitkin, T. V. Pestova, S. V. Maslova, and V. I. Agol, "Point mutations modify the response of poliovirus RNA to a translation initiation factor: a comparison of neurovirulent and attenuated strains," Virology, vol. 166, no. 2, pp. 394-404, 1988.

[8] R. M. Kinney, G.-J. Chang, K. R. Tsuchiya, et al., "Attenuation of Venezuelan equine encephalitis virus strain TC-83 is encoded by the $5^{\prime}$-noncoding region and the E2 envelope glycoprotein," Journal of Virology, vol. 67, no. 3, pp. 12691277, 1993.

[9] R. J. Kuhn, D. E. Griffin, H. Zhang, H. G. M. Niesters, and J. H. Strauss, "Attenuation of Sindbis virus neurovirulence by using defined mutations in nontranslated regions of the genome RNA," Journal of Virology, vol. 66, no. 12, pp. 7121-7127, 1992.

[10] S. Butrapet, C. Y. H. Huang, D. J. Pierro, N. Bhamarapravati, D. J. Gubler, and R. M. Kinney, "Attenuation markers of a candidate dengue type 2 vaccine virus, strain 16681 (PDK53 ), are defined by mutations in the $5^{\prime}$ noncoding region and nonstructural proteins 1 and 3," Journal of Virology, vol. 74, no. 7, pp. 3011-3019, 2000.

[11] R. M. Kinney, S. Butrapet, G.-J. J. Chang, et al., "Construction of infectious cDNA clones for dengue 2 virus: strain 16681 and its attenuated vaccine derivative, strain PDK-53," Virology, vol. 230, no. 2, pp. 300-308, 1997. 
[12] D. E. Alvarez, M. F. Lodeiro, C. V. Filomatori, S. Fucito, J. A. Mondotte, and A. V. Gamarnik, "Structural and functional analysis of dengue virus RNA," Novartis Foundation Symposium, vol. 277, pp. 120-132, 2006.

[13] C. V. Filomatori, M. F. Lodeiro, D. E. Alvarez, M. M. Samsa, L. Pietrasanta, and A. V. Gamarnik, "A 5' RNA element promotes dengue virus RNA synthesis on a circular genome," Genes and Development, vol. 20, no. 16, pp. 2238-2249, 2006.

[14] A. J. Macadam, G. Ferguson, J. Burlison, et al., "Correlation of RNA secondary structure and attenuation of sabin vaccine strains of poliovirus in tissue culture," Virology, vol. 189, no. 2, pp. 415-422, 1992.

[15] N. Bhamarapravati and Y. Sutee, "Live attenuated tetravalent dengue vaccine," Vaccine, vol. 18, supplement 2, pp. 44-47, 2000.

[16] N. Bhamarapravati, S. Yorksan, and T. Chayaniyayothin, "Immunization with a live attenuated dengue-2-virus candidate vaccine (16681-PDK 53): clinical, immunological and biological responses in adult volunteers," Bulletin of the World Health Organization, vol. 65, no. 2, pp. 189-195, 1987.

[17] S. Yoksan, N. Bhamarapravati, and S. B. Halstead, "Dengue virus vaccine development: study on biological markers of uncloned dengue 1-4 viruses serially passaged in primary cells," in Proceedings of the 4th Symposium on Arbovirus Research, T. D. George, Ed., pp. 35-38, Brisbane, Australia, May 1986.

[18] C. Y.-H. Huang, S. Butrapet, D. J. Pierro, G.-J. J. Chang, A. R. Hunt, N. Bhamarapravati, D. J. Gubler, and R. M. Kinney, "Chimeric dengue type 2 (vaccine strain PDK-53)/dengue type 1 virus as a potential candidate dengue type 1 virus vaccine," Journal of Virology, vol. 74, no. 7, pp. 3020-3028, 2000.

[19] C. Y.-H. Huang, S. Butrapet, K. R. Tsuchiya, N. Bhamarapravati, D. J. Gubler, and R. M. Kinney, "Dengue 2 PDK53 virus as a chimeric carrier for tetravalent dengue vaccine development," Journal of Virology, vol. 77, no. 21, pp. 1143611447, 2003.

[20] C. Y.-H. Huang, S. J. Silengo, M. C. Whiteman, and R. M. Kinney, "Chimeric dengue 2 PDK-53/West Nile NY99 viruses retain the phenotypic attenuation markers of the candidate PDK-53 vaccine virus and protect mice against lethal challenge with West Nile virus," Journal of Virology, vol. 79, no. 12, pp. 7300-7310, 2005.

[21] S. Butrapet, R. M. Kinney, and C. Y.-H. Huang, "Determining genetic stabilities of chimeric dengue vaccine candidates based on dengue 2 PDK-53 virus by sequencing and quantitative TaqMAMA," Journal of Virological Methods, vol. 131, no. 1, pp. $1-9,2006$.

[22] M. Zuker, "Mfold web server for nucleic acid folding and hybridization prediction," Nucleic Acids Research, vol. 31, no. 13, pp. 3406-3415, 2003.

[23] K. C. Leitmeyer, D. W. Vaughn, D. M. Watts, et al., "Dengue virus structural differences that correlate with pathogenesis," Journal of Virology, vol. 73, no. 6, pp. 4738-4747, 1999.

[24] W. Sirigulpanit, R. M. Kinney, and V. Leardkamolkarn, "Substitution or deletion mutations between nt 54 and 70 in the $5^{\prime}$ non-coding region of dengue type 2 virus produce variable effects on virus viability," Journal of General Virology, vol. 88, no. 6, pp. 1748-1752, 2007. 

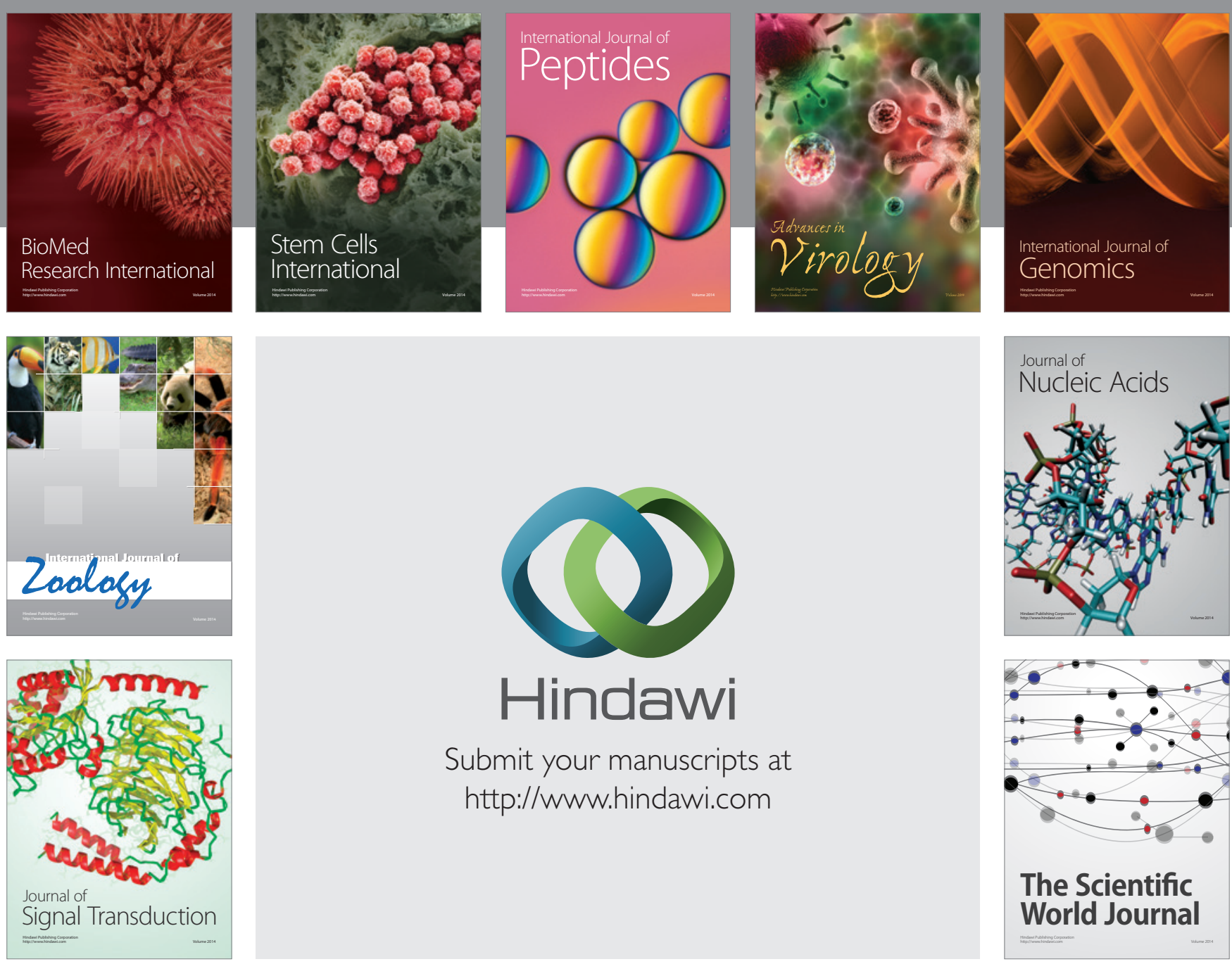

Submit your manuscripts at

http://www.hindawi.com
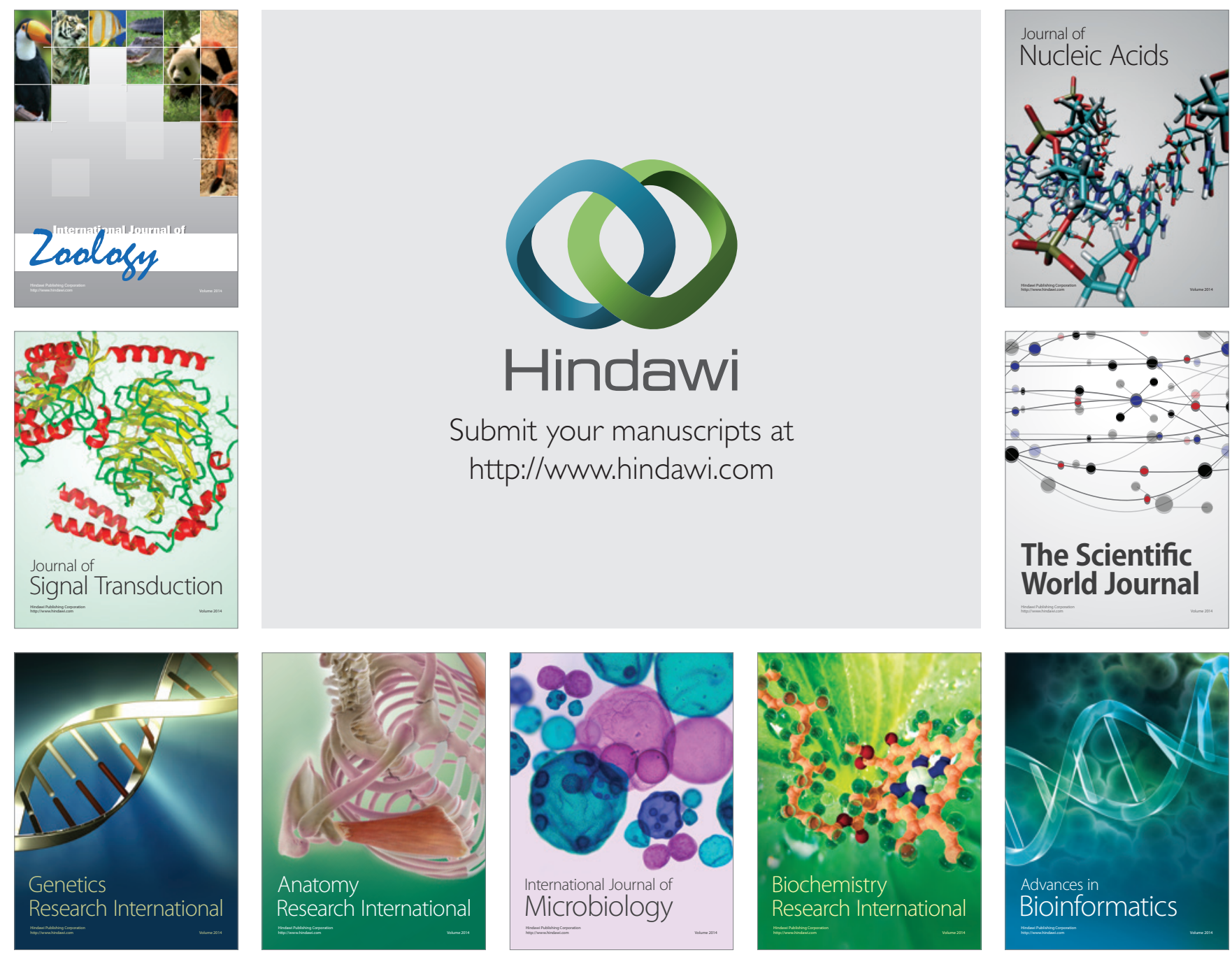

The Scientific World Journal
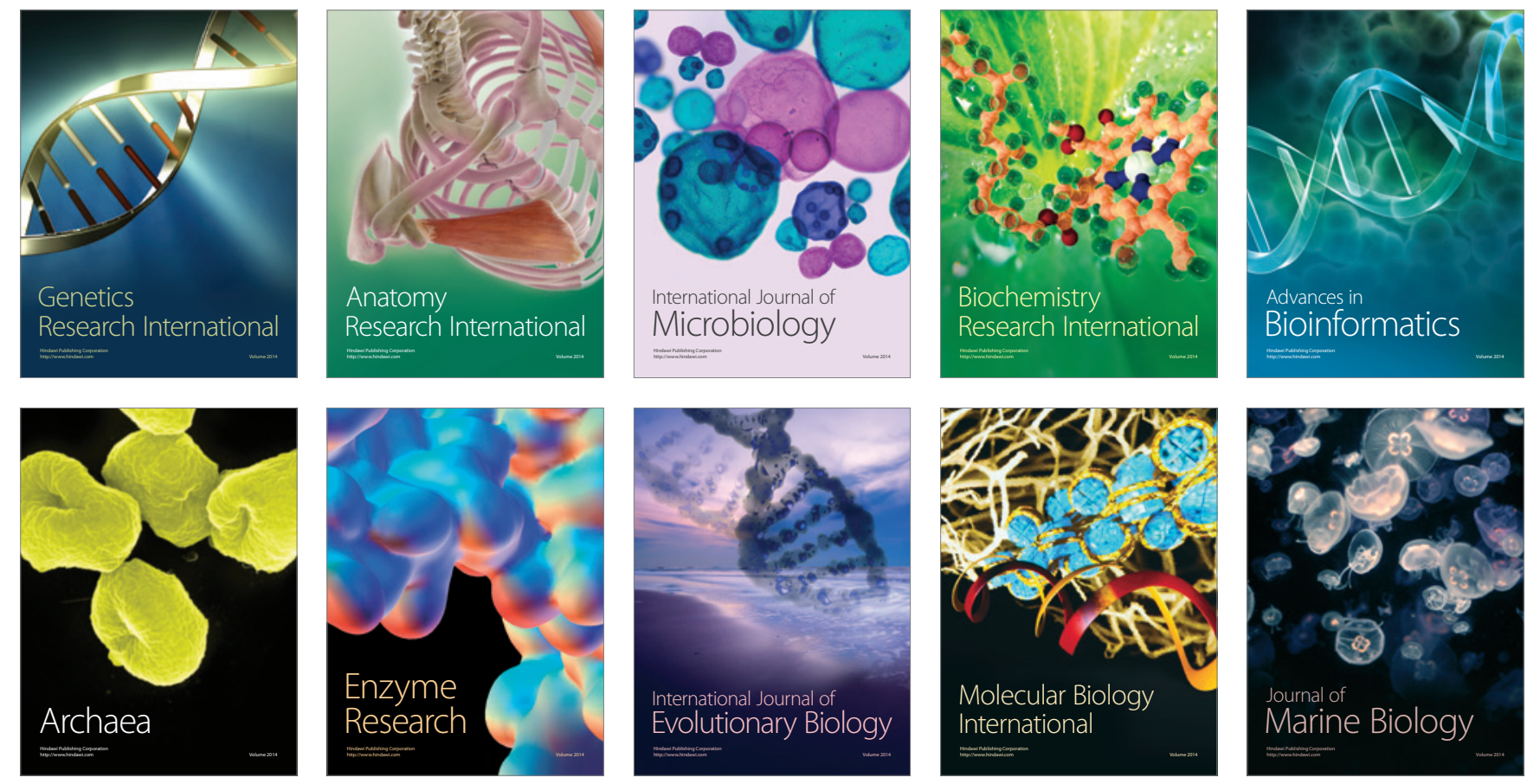